\title{
A (RE)PRODUÇÃO DE ESTEREÓtIPOS DE GÊNERO EM LIVROS DIDÁTICOS À LUZ DA ANÁLISE DE DISCURSO CRÍTICA
}

\author{
Maria Regina de Lima Gonçalves Oliveira \\ Ariovaldo Lopes Pereira \\ Universidade Estadual de Goiás (UEG), Goiânia, Goiás, Brasil
}

Resumo: Com base nos princípios da Análise de Discurso Crítica (ADC), este artigo objetiva analisar a (re)produção de estereótipos de gênero veiculados imageticamente em um livro didático de língua portuguesa da $1^{\text {a }}$ série do ensino fundamental. Para este estudo, nos aportamos teoricamente a autoras/es que discutem a (re)produção de estereótipos de gênero com base na ADC (FAIRCLOUGH, 2001), bem como a uma pesquisa documental realizada em livro didático (FERREIRA, 2014; PEREIRA, 2014). Nesta pesquisa, encontramos como principais resultados: a predominância de personagens masculinos, principalmente quando a temática se refere a profissões; a associação da mulher ao consumismo; dentre outros.

Palavras-chave: Análise de Discurso Crítica. Livro didático. Estereótipos de gênero. Língua portuguesa.

INTRODUÇÃO

Este trabalho tem como objetivo principal analisar a (re)produção de estereótipos de gênero veiculados pelas imagens presentes em um livro didático de Língua Portuguesa. $O$ estudo aqui apresentado restringe-se aos cinco primeiros capítulos da coleção Eu gosto (PASSOS; SILVA, 2014), do $1^{\circ}$ 
ano do Ensino Fundamental, a qual é distribuída pelo Programa Nacional do Livro Didático (PNLD) na cidade de Crixás, estado de Goiás.

A discussão que segue surgiu da preocupação de entender quando há e como se dá a produção de estereótipos de gênero. Atentando-nos aos livros didáticos usados amplamente na rede municipal de ensino, percebemos a veiculação de imagens que podem, conscientemente ou não, propagar/ produzir/reproduzir os papéis sociais impostos - contraditoriamente - à mulher e ao homem.

Guacira Lopes Louro (2000; 2014), pesquisadora que associa a temática de gênero à educação, ilustra de forma veemente o que abordamos neste estudo, pois para a autora, nesse campo, a educação, e mais precisamente a escola, possui como preocupação magna a manutenção da hegemonia e do binarismo. Esse aspecto pode ser percebido tanto nas práticas pedagógicas (brincadeiras que separam meninas e meninos/restrições às meninas etc.), quanto nos manuais de ensino usados em sala de aula. Estes últimos, objeto de pesquisa deste trabalho, com seu conteúdo direcionador, podem limitar a prática docente à mera reprodução, além de fixar os métodos de exposição da aula, pois, conforme reforça Lajolo (1996, p. 4), é o livro didático que acaba "determinando conteúdos e condicionando estratégias de ensino, marcando, pois, de forma decisiva, o que se ensina e como se ensina o que se ensina".

A partir das considerações de Lajolo (1996), podemos depreender que o livro didático demarca as fronteiras do fazer docente no que concerne ao processo de ensino e aprendizagem, pois direciona a metodologia, propõe conteúdos, sugere e às vezes determina a forma que esses conteúdos serão trabalhados. Em outras palavras, trata-se de uma espécie de'manual'a ser seguido, muitas vezes sem nenhuma contestação por parte dos agentes de ensino.

Essa prática (in)consciente contribui para a legitimação de padrões hegemônicos, acenando àquilo que se entende por adequado para meninas e meninos; impondo modelos a serem adotados sem nenhum questionamento ou crítica. Nesse sentido, o livro didático pode ser considerado uma forma de manutenção/fixação da hegemonia de determinados comportamentos relacionados a cada gênero, a qual se mostra imageticamente nas brincadeiras/brinquedos, profissões, roupas etc.

Nessa perspectiva, propomos para a discussão a revisão teórica baseada principalmente em Louro (2000; 2014), Butler (2003), Moita Lopes (2002), Resende e Ramalho (2006), Fairclough (2001), Ferreira (2014), Toscano (2000), como suporte para a análise documental da coleção Eu gosto (PASSOS; SILVA, 2014), de Língua Portuguesa, mencionada anteriormente. Para isso, 
dividimos o trabalho em seções, nas quais discutimos, com base no referencial teórico adotado: a construção social de gênero e as práticas discursivas; os estereótipos de gêneros em livros didáticos; a metodologia norteadora do trabalho; e a apresentação e análise dos dados.

\section{A CONSTRUÇÃO SOCIAL DE GÊNERO E AS PRÁTICAS DISCURSIVAS}

para fins de conceituação, entendemos gênero a partir da ótica pós-estruturalista, a qual o percebe, assim como a sexualidade, como um construto social e cultural não pertencente ao sistema compulsório sexo/ gênero (BUTLER, 2003; LOURO, 2014), haja vista que esse princípio é regido pela oposição binária - homem/mulher - de forma que intrinsecamente há a consolidação da hierarquia dominador/dominada, respectivamente.

Dessa forma, seguimos as esteiras de Butler (2003), ao rejeitarmos a imposição social que naturaliza as dimensões sexo e gênero, posto que essas categorias são construídas historicamente/socialmente/culturalmente ante as práticas discursivas nas quais nos inscrevemos. Não há, nesse sentido, construtos precedentes à cultura, nem mesmo determinações pré-sociais assentadas no plano biológico; há sim, contrariamente, construções que se dão por meio dos confrontos culturais e sociais.

A partir dessa constatação, entendemos que as identidades sociais são estabelecidas por meio de práticas discursivas, ou seja, elas são construídas a partir do discurso e podem ser igualmente contrapostas por esse mesmo elemento, ou ainda ser legitimadas também por ele (RESENDE; RAMALHO, 2006).

Com isso, concebemos o discurso como campo das relações de poder instanciadas na sociedade (FOUCAULT, 1979), no qual as identidades são construídas a partir do contexto social à qual se vinculam. Consequentemente, podemos afirmar que as identidades são forjadas pelos diferentes discursos aos quais os sujeitos estão expostos; em outras palavras, essa construção social é envolta pelas relações de poder concernentes à sociedade na qual estamos inseridos.

Nessa direção, Hall (2006) corrobora a compreensão de identidade aqui adotada, pois para ele, na perspectiva pós-moderna, os sujeitos não possuem uma identidade fixa, estável e permanente, mas, inversamente, as identidades são múltiplas e encontram-se em constante (trans)formação. Nesse percurso, ainda de acordo com o autor, sofremos influência pela forma de interpretação que a/o outra/o faz de nós, ou seja, somos moldados nos e pelos regimes culturais dos quais fazemos parte. 
A partir da compreensão dada por Butler (2003) e Louro (2014), depreendemos que a construção de gênero, ao contrário do que prega a visão biologicista, não é estanque e nem naturalizada (dada no nascimento), mas produzida e reproduzida por meio das práticas discursivas, nas quais nos construímos e reconstruímos. Diante disso, conforme ilustra Fairclough (2001, p. 64), "o discurso se relaciona dialeticamente com a estrutura social contribuindo para a constituição de todas as dimensões dessa estrutura".

O discurso perpassa as dimensões sociais nas quais somos constituídas/os e assim, conforme situa Moita Lopes (2009, p. 15), "nós somos o discurso que circulamos: eles nos constroem, ou seja, a linguagem não nos representa simplesmente, mas nos constrói". Percebemos, com isso, que os discursos fazem parte de uma convenção que negocia socialmente as normas que regem, por exemplo, o feminino e o masculino. Em outras palavras, o discurso acontece num dado contexto social/cultural/histórico que, por sua vez, reitera, concomitantemente, aquilo que se entende por adequado nas relações de gênero e nos meandros da sexualidade.

Nessa perspectiva, Butler (2003) defende que a construção de gênero é um ato performativo, o que significa dizer que as identidades sociais se constroem e reconstroem ante a linguagem; trata-se de um "vir a ser". Corroboram, nesse sentido, Livia e Hall (2010) em "É uma menina!": a volta da performatividade à linguística' ${ }^{1}$, quando fazem alusão à construção enunciativa do ser feminino, uma vez que, ao inscrever uma condição/posição que o novo ser deve ocupar, está-se designando atitudes que se esperam serem assumidas por ele. Torna-se evidente, assim, que as constituições e re-constituições de gênero são balizadas pela linguagem e, nesse sentido, a construção de gênero é um ato performativo.

Oliveira (2016, p. 556), ao mencionar Austin (1990), afirma que "a relevância da linguagem se concentra em sua característica performativa, ou seja, a linguagem consistiria numa ação (performance) ocorrida no momento da enunciação". Nesse caminho, vemos que o conceito de ato de fala desenvolvido por Austin (1990) designa que ao dizermos algo estamos, na verdade, acenando nossa intenção em fazer algo.

Com base nesses entendimentos, percebemos que a formação de estereótipos de gênero é uma construção concernente ao âmbito social/cultural, ganhando respaldo por meio da reiteração discursiva que é diariamente legitimada pelas diferentes instâncias. Pensando nisso, discutimos no tópico seguinte a (re)produção desses estereótipos de gênero em livros didáticos, na busca de compreender como esses manuais de ensino corroboram essa formação estereotipada. 


\section{ESTEREÓTIPOS DE GÊNERO EM LIVROS DIDÁTICOS}

como visto, a (re)produção de estereótipos de gênero acontece discursivamente e de forma tão naturalizada que se torna impossível evidenciar com exatidão quando esse processo se inicia. Entretanto, sabemos que os discursos hegemônicos ganham força a partir das reiterações sociais promovidas pelo Estado, a mídia, a igreja e a escola (MAGALHÃES, 2008). Diante disso, o livro didático, como um dos principais recursos utilizados em sala de aula ainda nos dias atuais, pode ser entendido a partir da ótica discursiva como instrumento que, para além de "seu caráter instrucional, exerce também uma função formadora na constituição dos indivíduos que o acessam" (PEREIRA, 2014). Isso implica dizer que o livro didático se vincula à realidade da qual fazemos parte e desempenha com isso, "importante papel no processo de produção e reprodução de práticas sociais" (PEREIRA, 2014, p. 206).

Dessa forma, compreendemos esse manual de ensino como um instrumento dotado de discursos ideológicos que podem, contraditoriamente, tanto gerar o acatamento e a submissão, quanto a crítica e a resistência (PEREIRA, 2014). Nesse sentido, analisamos sob a égide da Análise de Discurso Crítica, quais estereótipos o livro didático (re)produz, seguindo, para tanto, as considerações de Toscano (2000), a qual menciona que as ideologias hegemônicas estão presentes não somente nos textos, mas também nas imagens desses manuais.

Nessa perspectiva, entendemos a escola como importante ambiente para as construções e re-construções identitárias, pois é a partir desses contextos institucionais que as/os agentes de ensino - docentes e discentes - se constituem como sujeitos sociais (MOITA LOPES, 1998). Em decorrência disso, os discursos veiculados pelos livros didáticos fazem parte desse modo de percepção social, do qual fazemos parte.

A formação de estereótipos de gênero no campo educacional ilustra o poder subjacente à linguagem, capaz de "não apenas expressar relações, poderes, lugares", mas de instituí-los e de produzir e fixar diferenças (LOURO, 2014 p. 69). Daí, podemos depreender que a prática discursiva atravessa e molda nossas práticas sociais de forma tão natural que, com o reforço diário, cristalizamos comportamentos e atitudes, numa crença desmedida de que foram dadas naturalmente/biologicamente.

De acordo com Van Dijk (2015, p. 150), "os livros didáticos e os ensinos neles baseados formam o crisol discursivo para a reprodução cotidiana das crenças étnicas preconceituosas e, frequentemente, as práticas discriminatórias nelas baseadas". Torna-se evidente assim que as 
representações estereotipadas de mulheres e homens presentes nesses manuais de ensino contribuem massivamente para a reprodução acrítica dos padrões hegemônicos, uma vez que os discursos que circundam ali são tidos como verdadeiros e incontestáveis por parte daquelas/es que o acessam.

Metodologia

À luz do quadro teórico traçado pela díade gênero-linguagem (MOITA LOPES, 2002; BUTLER, 2003), bem como dos desígnios propostos pela Análise de Discurso Crítica (FAIRCLOUGH, 2001), inscrevemos este artigo de cunho qualitativo na linha bibliográfica-documental de pesquisa, uma vez que nos interessa uma abordagem teórica reforçada pela análise do livro didático de Língua Portuguesa do $1^{\circ}$ ano do Ensino Fundamental. Nesse percurso, restringimos a análise aos cinco primeiros capítulos da coleção Eu gosto (PASSOS; SILVA, 2014) da disciplina de Língua Portuguesa.

Para Lüdke e André (1986, p. 39), análises documentais não são apenas "uma fonte de informação contextualizada"; para além disso, "surgem num determinado contexto e fornecem informações sobre esse mesmo contexto". Depreendemos com isso que o princípio da pesquisa documental em livros didáticos baseia-se na identificação de informações que podem dar subsídio à problematização inicial do trabalho, assim como para as/os autoras/es trazidas/os à cena teórica, além de oferecer possíveis respostas às buscas empreendidas aqui.

Revestimos nossa análise de uma perspectiva qualitativa por concordarmos com as considerações de Rampazzo (2005, p. 60), quando o autor afirma que nesse tipo de pesquisa "todos os fenômenos são igualmente importantes e preciosos: a constância das manifestações e sua ocasionalidade, a frequência e a interrupção, a fala e o silêncio". Para ele, na abordagem qualitativa há uma compreensão/valorização das experiências que cada sujeito tem.

Assim, nesse contexto, iniciamos este estudo com a revisão bibliográfica, vista por Gil (2008) como aquela que tem por base trabalhos já publicados; na sequência, empreendemos uma análise do livro didático Letramento e Alfabetização seguindo as esteiras da Análise de Discurso Crítica, a fim de traçar um diálogo entre o aporte teórico e os discursos veiculados por imagens presentes no material pesquisado.

Sobre a escolha, analisamos os cinco primeiros capítulos da coleção por percebermos em olhares preliminares a constância de imagens que evidenciam/expressam/sugerem a (re)produção dos estereótipos de gênero. Ressaltamos que embora a análise tenha ocorrido ao longo de cinco capítulos, não serão apresentadas todas as imagens, devido à limitação de espaço. 
Assim, elas serão apresentadas de forma aleatória (em relação aos capítulos), de acordo com sua relevância para a pesquisa (conforme nossa seleção).

\section{APRESENTAÇÃO E ANÁLISE DOS DADOS}

As imagens são associadas, por vezes, com a representação da realidade que nos circunda e, exatamente por esse caráter social, são atravessadas pelo plano simbólico, isto é, pelos ideais cristalizados do imaginário social². Em outras palavras, a análise imagética permite descortinar o invisível e evidenciar a materialidade discursiva presente ao texto. Nessa direção, analisamos sob o enfoque já demarcado o primeiro capítulo, denominado "Os sinais", numa referência aos sinais de trânsito, expresso na imagem 1 .

Figura 1 - Capítulo I.

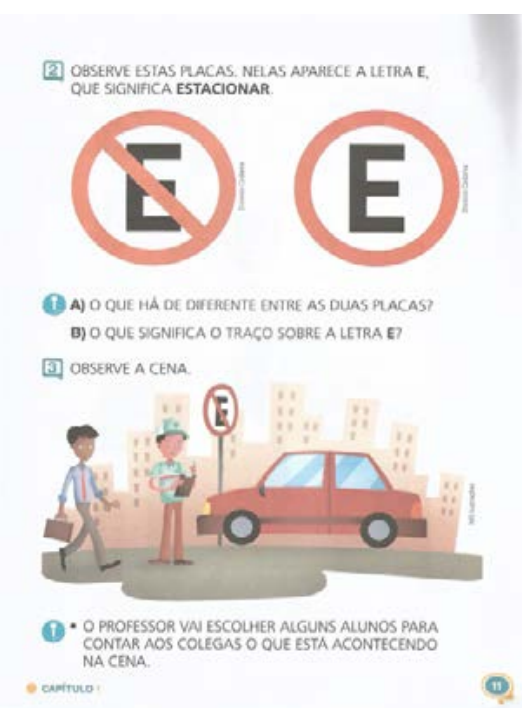

Fonte: (PASSOS; SILVA, 2014, p. 11).

O capítulo I possui oito páginas e, devido à sua pequena extensão, julgamos pertinente o fato de duas laudas ${ }^{3}$ fazerem referência a personagens masculinos. Percebemos a predominância dessa categoria social relacionada a um assunto estereotipado socialmente como pertencente ao campo de atuação do homem, haja vista que o capítulo trata dos sinais/placas, numa alusão principal ao trânsito. Vemos, com isso, o respaldo didático à (re)produção de estereótipos de gênero, o que expressa de forma veemente aquilo que se entende por adequado para o feminino e para o masculino (TOSCANO, 2000). 
Torna-se evidente, numa análise do não-visto, que a mulher é inerente a outro ambiente, ou seja, enquanto o homem trabalha, pratica esportes e/ou passeia, ela se ocupa de outras questões (invisíveis). Usando como pano de fundo a análise do discurso - sob o viés analítico que se propõe a descortinar para além do dito, ou seja, o não-dito, mas que de alguma forma ficou subtendido (ORLANDI, 2012) -, manifesta-se nesse capítulo a supressão feminina por meio de seu apagamento e ainda ficam encobertos alguns questionamentos, tais como: "onde elas estarão? O que fazem ou qual sua ocupação?"

Diante disso, e levando-se em consideração que os discursos são permeados pela prática, podemos afirmar que eles se fazem presentes cotidianamente na vida das pessoas, agindo de forma a moldar a maneira com que nos relacionamos com a realidade que nos circunda, o que consequentemente (re)significa os sentidos que atribuímos a ela ao longo da história.

$\mathrm{Na}$ imagem acima podemos notar, em meio às ruas e placas, personagens que de forma consciente ou não-consciente foram postos aí como aqueles que se vinculam a esse tema; intrínsecas a esse fato estão as relações de poder que hierarquizam a relação entre homens e mulheres. O discurso imagético, nesse caso, delimita os espaços sociais de gênero e determina o que é aconselhável para ele e para ela, numa visão binária e reprodutora dos moldes sociais.

Acerca desse poder, intrincado à prática discursiva, Fairclough (2001, p. 108) assevera que "alguns textos conduzem a guerras ou à destruição de armas nucleares; outros levam as pessoas a perder o emprego ou a obtê-lo; outros ainda modificam as atitudes, as crenças ou as práticas das pessoas". Depreendemos, a partir daí, que os estereótipos são (re)produzidos pelos discursos instanciados na sociedade, os quais instituem formas de ser/ comportar/agir.

Analisamos, na sequência, as imagens e o texto a elas associado, do capítulo III: 
Figuras 3 e 4 - Capítulo III.

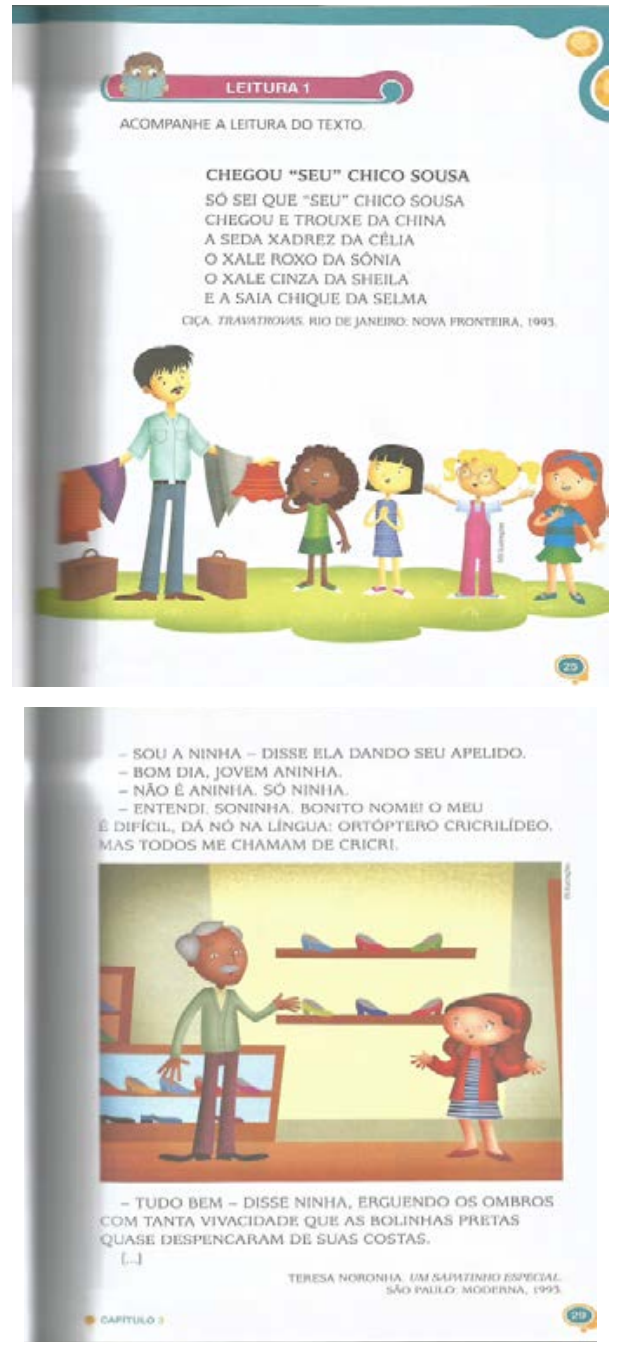

Fonte: (PASSOS; SILVA, 2014, p. 25 e 29).

No capítulo Ill vemos uma representação feminina e uma diminuição nas aparições masculinas, as quais ficam restritas à página 32 (objeto da próxima análise). $O$ título da seção é "Os nomes", e verificamos no decorrer das 11 páginas uma referência imagética à mulher, inclusive a nomes de mulheres. Concomitantemente, há a reverberação de valores capitalistas, nos quais se inscrevem o consumismo, por exemplo. Essa percepção é possível 
graças à expressão facial e corporal das personagens, numa demonstração de interesse e euforia - referente à venda/compra ou observação de bens materiais/presentes. Entretanto, o que torna o evento digno de nota aqui não se refere apenas aos aspectos capitalistas, mas à associação da categoria feminina a esse campo.

É crucial que se note a frequência de personagens femininos para representar o interesse pelos objetos destacados nas imagens e no texto (xale e sapatos), bem como que a profissão apresentada - a de vendedor/a - é representada por homens; trata-se de outra associação que reitera os papéis sociais e fixa padrões de gêneros.

De forma complementar, julgamos importante a seguinte ilustração, ainda do capítulo III:

Figura 5 - Capítulo III.

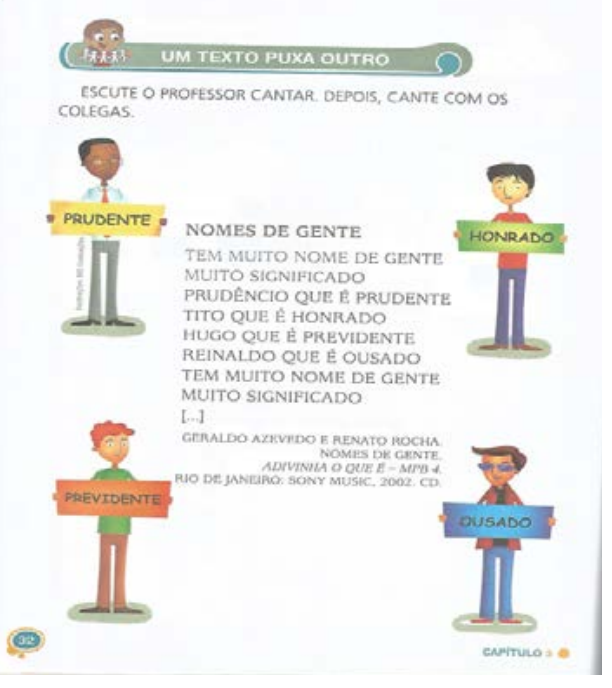

Fonte: (PASSOS; SILVA, 2014, p. 32).

Vemos aqui que, numa alusão ao texto que compõe a imagem, alguns personagens seguram placas com diferentes adjetivos. Além disso, é evidente uma tentativa de caracterização equivalente ao adjetivo "segurado", vemos isso na vestimenta e nos adereços utilizados pelos personagens. Em outras palavras, implícita a essa ilustração está a re-afirmação no plano simbólico de que tais características são inerentes ao homem e inadequadas às mulheres (circunscritas ao plano invisível). $O$ recuso imagético institui aquilo que 
emerge do imaginário social, refletindo com isso as práticas desse campo e as aspirações inerentes a ele.

Por meio da análise das três imagens escolhidas do capítulo III, podemos afirmar que há duas manifestações empreendidas nesse ínterim, a saber, o visível e o invisível (TASSO; GONÇALVES, 2012). Lemos nas duas primeiras imagens que as personagens em sua maioria são meninas (que ganham presentes ou que compram sapatos) que estão imersas no campo capitalista do consumo e daí vemos a visibilidade dada à mulher como aquela que se interessa por fazer compras ou por ganhar presentes; já o homem é representado por um personagem que vende/presenteia mulheres. Há implícita a esse recurso imagético a associação da mulher às imposições capitalistas, bem como do homem à profissão e/ou liberdade para viajar e presentear. Já na última imagem do capítulo, lemos que os personagens são todos homens. Intrincada a esse fato está a invisibilidade da mulher, a qual, nesse contexto, não está presente nas placas ou na orientação delas, assim como não se faz presente nas características apresentadas, já que elas estão num campo concernente à masculinidade. Ora, ser "ousadA" pode ter uma denotação diferente de ser "ousadO".

Escolhemos, por fim, a última ilustração do capítulo V, dada a relevância para a temática que propomos para apresentação aqui:

Figura 6 - Capítulo V.

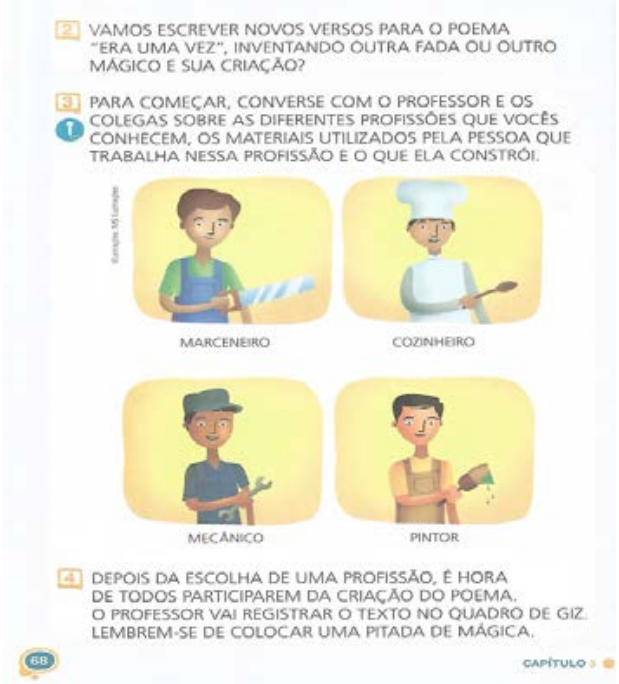

Fonte: (PASSOS; SILVA, 2014, p. 68). 
Vemos nessa imagem, exposta no capítulo $V$, o qual contém 16 páginas, a predominância de personagens masculinos numa referência ao tema profissões. Como mencionado anteriormente, nas figuras 3 e 4, há uma evidência maior dada ao homem quando o assunto é independência, liberdade e profissão. Entretanto, nessas ilustrações não havia descrição evidente da temática "trabalho", como há na figura 6. É relevante pensar que esse livro didático destina-se a meninas e meninos e que a representatividade é fator importante para as/os discentes, pois nessa imagem vemos a representação de personagens masculinos e o apagamento total da figura feminina.

A formação de estereótipos é uma constante nos capítulos analisados e é caracterizada por Bhabha (2007, p. 110) como"um modo de representação complexo, ambivalente e contraditório", ou seja, é "uma forma de conhecimento e identificação que vacila entre o que está sempre'no lugar', já conhecido, e algo que deve ser ansiosamente repetido [...]". Em outras palavras, a (re)produção de estereótipos se basta por seu caráter "naturalizador" e, com isso, não necessita de comprovação; logo, eles são apreendidos como verdades que não admitem contestação e se formam a partir da repetição/ reiteração social num dado momento histórico e discursivo.

Entendemos, assim, que o estereótipo se forma com base no discurso ambivalente e dominante: "os sujeitos são sempre colocados de forma desproporcional em oposição ou dominação através do descentramento simbólico de múltiplas relações de poder" (BHABHA, 2007, p. 113). Nesse sentido, depreendemos, a partir das imagens analisadas, que o processo de hierarquização de mulheres sob a 'tutela' masculina continua a vigorar nos manuais de ensino, pois há, nas ilustrações, conforme colaboração de Toscano (2000, p. 40), uma evidente

[s] uperioridade que os autores - consciente ou inconscientemente - atribuem aos personagens masculinos. Esta pretensa superioridade é tão evidente que mesmo os livros que mostram tendência a um tratamento mais igualitário, entre meninos e meninas, registram ostensiva inferioridade quanto ao número de vezes que "elas" aparecem nas ilustrações, em relação a "eles".

Para Ferreira (2014) é necessário, para além de um olhar crítico no momento de escolha dos livros didáticos, uma formação inicial das/ os docentes que considere a diversidade cultural existente no nosso país, os estudos feministas, de gênero/sexualidade, raça etc., bem como que as editoras e autoras/es desses manuais de ensino reflitam sobre tais temáticas no processo de escrita, para que, assim, esse conhecimento se faça presente nos discursos textuais e imagéticos que circulam nos livros didáticos e na 
prática pedagógica. Ou seja, "que os LD [livros didáticos] possam demonstrar a realidade do povo brasileiro e que não sejam disseminadas as questões ideológicas e de poder e que privilegiam somente um grupo de pessoas." (FERREIRA, 2014, p. 113).

Nessa direção, Toscano (2000, p. 13) corrobora a importância de um posicionamento crítico da escola face às questões aclamadas neste estudo pois, para ela,

Não raro, ao invés de pôr-se na vanguarda da mudança, ela [a escola] tem optado pelo imobilismo, pelo menos no que tange à questão - para nós crucial - da plena integração da mulher à sociedade urbano-industrial, cujo modelo tanto valorizamos. Na escola brasileira, podemos identificar um verdadeiro feudo, onde sobrevivem, não raro, as relações mais arcaicas do binômio homem-mulher, pouco diferentes das que predominavam na época da educação segregada por sexos.

Para Toscano (2000), a escola, com seu corpo docente e materiais/ recursos de ensino, desempenha papel magno nesse processo de (re) produção de estereótipos de gênero, e embora sua pesquisa sobre livros didáticos já tenha quase 20 anos, poucas mudanças ocorreram nesse campo, haja vista que tais instâncias sociais continuam a educar diferentemente meninas e meninos, conforme visto nesta pesquisa.

Sobre esse tratamento diferenciado, Auad $(2016$, p. 77) reforça que"a escola, assim como outras instituições sociais, ressalta e utiliza as diferenças e transforma-as em desigualdades". Assim, as diferenças biológicas que separam mulheres e homens ganham outras tonalidades nesses ambientes de ensino - nos quais o livro didático se faz presente como principal mediador da relação professora/or-aluna/o - não deixando "[n]enhuma dúvida de que a divisão dos papéis sociais, rigidamente limitados pelo sexo biológico dos atores sociais, é um dos mais evidentes sinais de discriminação de gênero, com desdobramentos em outras esferas da vida social." (TOSCANO, 2000, p. 31).

Como já visto, a partir das análises realizadas e por entendermos a importância do livro didático para o processo de ensino e aprendizagem, percebemos a influência desse material de ensino para a propagação de estereótipos de gênero. Compreendemos, nesse contexto, que, embora seja concernente à/ao profissional docente a perspectiva de ensino adotada, compete a essa categoria abordar criticamente os conteúdos educacionais. Esses manuais inculcam e conformam identidades de gênero por meio de diferentes recursos, tais como o discurso imagético. 


\section{CONSIDERAÇÕES FINAIS}

Com base no estudo realizado, podemos afirmar que as identidades de gênero são construídas a partir do confronto social, histórico e discursivo empreendido em nossas vivências enquanto ser social (FERREIRA, 2014). A essa construção se relacionam outras dimensões - a saber, raça, classe, sexualidade - que perfazem as diferentes identidades que assumimos socialmente. Intrínsecas a essas categorias estão questões de poder que hierarquizam e inculcam ideais como forma de manutenção das desigualdades sociais de gênero, por exemplo.

Nessa perspectiva, o que falamos/fazemos (BUTLER, 2003) nos posiciona enquanto sujeitos sociais e, consequentemente, nos identifica também, assim como assevera Ferreira (2014, p. 96): “[o] que é dito e feito por uma pessoa que se posiciona com uma identidade de mulher, branca, classe média e heterossexual, não é visto e entendido da mesma forma se for dito por uma mulher, negra, classe média e heterossexual". Nesse sentido, a autora ainda acrescenta que

[a]s construções sociais que são feitas sobre determinados grupos, e que foram sendo construídas socialmente e historicamente, possibilitam que um grupo de pessoas tenha privilégio sobre outros grupos de pessoas. São privilégios que perpassam pelas questões de raça, de gênero, de sexualidade, e de classe. (FERREIRA, 2014, p. 96)

Vemos aqui, que a desigualdade de gênero, isto é, o privilégio de um grupo (homens) em detrimento de outro (mulheres), corrobora para a manutenção da (re)produção de estereótipos que se reiteram e se naturalizam discursivamente. Lemos nas imagens do livro didático analisado manifestações evidentes dessas características.

Embora, como já mencionado, saibamos do viés crítico de abordagem dos livros didáticos, nos quais os conteúdos que estereotipam a relação de gênero podem ganhar outra roupagem - a de resistência -, percebemos que esses manuais de ensino funcionam como instrumento capaz de moldar atitudes, bem como de naturalizar as desigualdades de gênero, conformando meninas à pretensa inferioridade instituída, pois de acordo com Auad (2016, p. 41) os livros didáticos "representam verdadeiros modelos para meninas $e$ meninos e garantem, no interior do sistema educativo, lugar de destaque para as desigualdades". Desta forma, para a autora, os materiais didáticos acabam sendo uma forma de "reforçar imagens e práticas hierarquicamente diferenciadas entre o masculino e o feminino." (AUAD, 2016, p. 41). 
Sob o enfoque da Análise de Discurso Crítica compreendemos, a partir da pesquisa empreendida aqui, que a perspectiva adotada pela coleção Eu gosto (PASSOS; SILVA, 2014), de Língua Portuguesa, mantém ranços patriarcais que reverberam padrões hegemônicos de gênero, assim como reforçam tais ideias. Nesse contexto, concordamos com a concepção de escola expressa por Moita Lopes (2008, p. 143): "uma agência importante na constituição de quem somos e seus discursos podem legitimar outros sentidos sobre quem podemos ser".

Em suma, depreendemos que, se, por um lado, a sala de aula e, mais precisamente, a ação docente e os recursos didáticos utilizados podem ser o lócus da resistência e da luta contra-hegemônica, por outro, tais instâncias podem legitimar/reverberar/instituir padrões estereotipados de gênero, nos quais a hierarquização homem/dominador-mulher/dominada e a naturalização dos papéis sociais são intrincadas aos livros didáticos adotados e repassadas de forma velada, quase imperceptível no processo de ensino e aprendizagem.

THE (RE)PRODUCTION OF GENDER STEREOTYPES IN TEXTBOOKS UNDER THE PRINCIPLES OF CRITICAL DISCOURSE ANALYSIS

ABSTRACT: Based on the principles of Critical Discourse Analysis (CDA), this article aims to analyze the (re)production of gender stereotypes conveyed in images printed in a first grade Portuguese language textbook. This study approaches authors who discuss the (re)production of gender stereotypes according to CDA (FAIRCLOUGH, 2001), as well as a documentary research done in a textbook (FERREIRA, 2014; PEREIRA, 2014). In this research, we found the following outcomes: the predominance of male characters, mainly when it comes to professions, and the association of women to consumerism, among others.

KeYwords: Critical Discourse Analysis. Textbook. Gender stereotypes. Portuguese language. 


\section{LA (RE)PRODUCÇIÓN DE ESTEREOTIPOS DE GÉNERO EN LIBROS DETEXTO A LA LUZ DEL ANÁLISIS DEL DISCURSO CRÍTICO}

Resumen: Basado en los principios del Análisis del Discurso Crítico (CDA), este artículo pretende analizar la (re)producción de estereotipos de género vehiculados imagéticamente en un libro de texto (LD) de lengua portuguesa del primer año de la enseñanza primaria. Para este estudio, nos sustentamos teóricamente en los autores que discuten la (re)producción de estereotipos de género basados en ADC (FAIRCLOUGH, 2001), así como una investigación documental realizada en los libros de texto (FERREIRA, 2014; PEREIRA, 2014). En esta investigación prevalecieron los siguientes resultados: predominancia de personajes masculinos, especialmente cuando el tema se refiere a profesiones; asociación de la mujer al consumismo; entre otros.

Palabras Clave: Análisis Crítico del Discurso. Libro de texto. Estereotipos de género. Lengua Portuguesa.

\section{NOTAS}

1 Texto traduzido por Rodrigo Borba e Cristiane Maria Schnack. Publicado em Linguagem, gênero, sexualidade - clássicos e traduzido sob organização de Ana Cristina Ostermann e Beatriz Fontana (2010).

2 De acordo com Carvalho (1987, p. 11)“O imaginário social é constituído e se expressa por ideologias e utopias [...]", sendo que:"Nele as sociedades definem suas identidades e objetivos, definem seus inimigos, organizam seu passado, presente e futuro [...]".

3 Embora tenhamos optado por apresentar apenas uma imagem.

\section{REFERÊNCIAS}

AUAD, D. Educar meninas e meninos: relações de gênero na escola. São Paulo: Contexto, 2016.

AUSTIN, J. L. Quando dizer é fazer: palavras e ação. Tradução de Danilo Marcondes. Porto Alegre: Artes Médicas, 1990.

BHABHA, H. K. O Local da Cultura. Belo Horizonte: UFMG, 2007.

BUTLER, J. Problemas de gênero: feminismo e subversão da identidade. Tradução de Renato Aguiar. Rio de Janeiro: Civilização Brasileira, 2003.

CARVALHO, J. M. A Formação das almas: o imaginário da república no Brasil. São Paulo: Companhia das Letras, 1987.

FAIRCLOUGH, N. [1992] Discurso e mudança social. Tradução de Izabel Magalhães. Brasília: UnB, 2001. 
FERREIRA, A. de J. (Org.). As políticas do Livro Didático e identidades sociais de raça, gênero, sexualidade e classe em livros didáticos. Campinas: Pontes, 2014.

FOUCAULT, M. Microfísica do poder. Organização e tradução de Roberto Machado. Rio de Janeiro: Graal, 1979.

GIL, A. C. Como elaborar projetos de pesquisa. 4. ed. São Paulo: Atlas, 2008.

Hall, S. A identidade cultural na pós-modernidade. 11. ed. São Paulo: DP\&A, 2006.

LAJOLO, M. Livro didático: um (quase) manual de usuário. Em aberto, Brasília, ano 16, n०69, p. 3-9, jan./mar. 1996.

LIVIA, A.; HALL, K. "É uma menina!": a volta da performatividade à linguística. Tradução de Rodrigo Borba e Cristiane Maria Schnack. In: OSTERMANN, Ana Cristina; FONTANA, Beatriz (Org.). Linguagem, gênero, sexualidade: clássicos traduzidos. São Paulo: Parábola, 2010.

LOURO, G. L. O corpo educado: pedagogias da sexualidade. Belo Horizonte: Autêntica, 2000.

. Gênero, sexualidade e educação: uma perspectiva pós-estruturalista. Petrópolis: Vozes, 2014.

LÜDKE, M.; ANDRÉ, M. E. D. A. Pesquisa em educação: abordagens qualitativas. São Paulo: EPU, 1986.

MAGALHÃES, I. Discursos e identidades de gênero na alfabetização de jovens e adultos e no Ensino Especial. Calidoscópio, São Leopoldo, v. 6, n. 2, p.61-68, mai./ago. 2008.

MOITA LOPES, L. P. Discurso de identidade na sala de aula de leitura em língua materna: a construção da diferença. In: SIGNORINI, I. (Org.). Língua(gem) e identidade. Campinas: Mercado de Letras, 1998.

MOITA LOPES, L. P. Identidades fragmentadas: a construção de raça, gênero e sexualidade na sala de aula. Campinas: Mercado de Letras, 2002.

MOITA LOPES, L. P. Sexualidades em sala de aula: discurso, desejo e teoria queer. In: MOREIRA, A. F.; CANDAU, V. M. (Org.). Multiculturalismo: Diferenças culturais e práticas pedagógicas. 3. ed. Rio de Janeiro: Vozes, 2008, p.125-148.

MOITA LOPES, L. P. A performance narrativa do jogador Ronaldo como fenômeno sexual em um jornal carioca. Revista da ANPOLL, Brasília, v. 2, n. 27, p.128-157, 2009.

OLIVEIRA, H. F. Indivíduos do sexo masculino no curso de Letras: performances discursivas, gênero e profissão docente. Revista brasileira Estudos Pedagógicos (on-line), Brasília, v. 97, n. 247, p. 552-569, set/dez. 2016.

ORLANDI, E. P. Discurso e leitura. São Paulo: Cortez, 2012.

PASSOS, C.; SILVA, Z. Letramento e Alfabetização: eu gosto. 5. ed. São Paulo: Ibep, 2014. 
PEREIRA, A. L. Identidades sociais de gênero em livros didáticos de língua estrangeira. In: FERREIRA, A. J. (Org.). As políticas do Livro Didático e identidades sociais de raça, gênero, sexualidade e classe em livros didáticos. Campinas: Pontes, 2014.

RAMPAZZO, L. Metodologia Científica: para alunos dos cursos de graduação e pós-graduação. 3. ed. São Paulo: Loyola, 2005.

RESENDE, V. de M.; RAMALHO, V. Análise de Discurso Crítica. São Paulo: Contexto, 2006.

TASSO, I.; GONÇALVES, R. F. C. R. Discurso imagético, representação e identidade indígena: questões teórico-analíticas. Estudos da Língua(gem), Vitória da Conquista, v. 10, n. 2 p. 125-142, dez. 2012.

TOSCANO, M. Estereótipos sexuais na educação: um manual para o educador. Petrópolis: Vozes, 2000.

VAN DIJK, T. A. Discurso e Poder. São Paulo: Contexto, 2015.

Maria Regima de Lima Gonçalves Oliveira: Mestranda do Programa Interdisciplinar Educação, Linguagem e Tecnologias da Universidade Estadual de Goiás (UEG). Especialista em Educação para a Diversidade, Cidadania e Direitos Humanos pela Universidade Federal de Goiás (UFG). Licenciada em Pedagogia pela UEG - Campus Crixás. Docente do quadro efetivo do município de Crixás- $\mathrm{GO}$.

E-mail: mariareginalima91@hotmail.com

Ariovaldo Lopes Pereira: Pós-doutorando em Estudos Linguísticos e Literários em Inglês na Universidade de São Paulo (USP). Doutor em Linguística Aplicada pela Universidade Estadual de Campinas Unicamp. Mestre em Linguística Aplicada pela Universidade de Brasília (UnB). Professor do Programa de Pós-Graduação Interdisciplinar em Educação, Linguagem e Tecnologias, da Universidade Estadual de Goiás (UEG).

E-mail: arylopes_br@yahoo.com 